\title{
Predicting adaptation to parenthood: The role of responsiveness, gratitude, and trust
}

\author{
HAGAR TER KUILE, ${ }^{a}$ ESTHER S. KLUWER,${ }^{a, b}$ CATRIN FINKENAUER, ${ }^{a}$ \\ AND TANJA VAN DER LIPPE ${ }^{a}$ \\ ${ }^{a}$ Utrecht University, The Netherlands and ${ }^{b}$ Radboud University, The Netherlands
}

\begin{abstract}
The influence of positive relationship processes, specifically perceived responsiveness, felt gratitude, and felt trust, on perceived adaptation to parenthood was investigated. It was hypothesized that both higher initial levels prior to pregnancy as well as increases over time in perceived responsiveness, felt gratitude, and felt trust predicted better adaptation to parenthood. Data from a five-wave longitudinal study of 109 newlyweds who became parents during the course of the study were used. Results showed that baseline positive relationship processes before pregnancy positively predicted adaptation to parenthood up to 4 years later. Changes over time were even stronger predictors of adaptation. Positive relationship processes may buffer against stressors during challenging life transitions, improving one's own adaptation as well the adaptation of one's partner.
\end{abstract}

The impact of the birth of the first child on the marital relationship has been the focus of a large body of research. The vast majority of studies conducted on this topic does not paint a rosy picture: The transition to parenthood has often been found to lead to declines in both marital and personal well-being (Kluwer, 2010; Twenge, Campbell, \& Foster, 2003). Couples report lower relationship satisfaction and sexual intimacy, increases in conflict, and higher levels of stress and depression after childbirth (Belsky \& Rovine, 1990; Doss, Rhoades, Stanley, \& Markman, 2009; Goodman, 2004; Kluwer \& Johnson, 2007).

Hagar ter Kuile, Department of Social and Organizational Psychology, Utrecht University, Utrecht, The Netherlands; Esther S. Kluwer, Department of Social and Organizational Psychology, Utrecht University, Utrecht, The Netherlands and Behavioural Science Institute, Radboud University, Nijmegen, The Netherlands; Catrin Finkenauer, Department of ISS: Cultural Diversity \& Youth, Utrecht University, Utrecht, The Netherlands; Tanja van der Lippe, Department of Sociology, Utrecht University, Utrecht, The Netherlands.

Correspondence should be addressed to Esther Kluwer, Utrecht University, Department of Social, Health and Organizational Psychology, 3508 TC Utrecht, The Netherlands, e-mail: E.s.kluwer@uu.nl.
The number of studies showing declines in relationship satisfaction after childbirth seems alarming, but the focus on relationship satisfaction does not capture the full extent of parents' experiences after childbirth. We know very little about how parents experience their own adaptation to parenthood and what factors facilitate or impede this experienced adaptation. Because a person's well-being has been found to be strongly influenced by how he/she perceives his/her own emotions and situation (Lyubomirsky, 2001), the current research aimed to investigate how new parents experience their own adaptation to parenthood.

We define perceived adaptation to parenthood as the degree to which parents experience the transition as difficult or easy and report high well-being after childbirth. Well-being in this case encompasses both relational and personal well-being, such as how worried parents are about changes in their lives and their new responsibilities as a parent, their satisfaction with changes since childbirth, their level of happiness since becoming parents, and how troubled parents are by common problems such as lack of sleep. How well parents adapt to parenthood not only affects 
their own well-being but indirectly also affects their relationship quality and the well-being of their children (Amato, 2001). Parental stress and depression are related to lower social competence and greater behavioral and emotional problems in children (Langrock, Compas, Keller, Merchant, \& Copeland, 2002). In addition, marital distress has been found to negatively affect the psychological and physical development of children (Amato, 2001). A better understanding of what factors contribute to parents' adaptation to parenthood could improve the support offered to first-time parents, hopefully preventing the negative consequences of low adaptation.

Although the majority of studies on the transition to parenthood have studied risk factors for the negative changes after childbirth, it is important to know more about factors that increase the coping capacity of first-time parents. We aim to provide the first test of how positive relationship processes are related to perceived adaptation to parenthood. Our reasoning is that positive relationship processes provide resources that will help first-time parents to deal with the challenges of the transition to parenthood. In addition, we aim to increase our understanding of how these positive relationship processes affect adaptation by applying models of relationship change to the transition to parenthood. That is, we test whether initial levels of positive processes that qualify the relationship prior to pregnancy versus changes in these processes across the transition to parenthood predict better adaptation. To address these goals, we used a longitudinal design with assessments of positive relationship processes before the first pregnancy, during pregnancy, and after childbirth among both fathers and mothers.

\section{Adaptation and positive relationship processes}

A useful theory on how couples adapt to potentially stressful events is the vulnerability-stress-adaptation (VSA) model (Karney \& Bradbury, 1995). According to the VSA model, personal resources and vulnerabilities can aggravate or diminish the impact of a stressful event on marital quality
(Karney \& Bradbury, 1995). Indeed, a number of moderators and predictors of well-being after childbirth have been identified. Demographic variables that have been found to negatively impact relational and personal well-being after childbirth are both high and low socioeconomic status, being female, and low occupational status (O'Hara \& Swain, 1996; Twenge et al., 2003). Social and personal factors associated with lower well-being are, among others, a lack of social support, lower marital adjustment (O'Hara \& Swain, 1996), greater conflict frequency (Kluwer \& Johnson, 2007), and poor conflict management before childbirth (Doss et al., 2009).

Instead of focusing on vulnerabilities, this study will look at partners' resources and how they predict adaptation to parenthood. Resources can be either practical, such as financial resources, or psychological, such as happiness or secure attachment. In this study, we focus on psychological resources present in the relationship. We investigate the role of perceiving responsiveness by the partner, feeling gratitude for the partner, and trusting the partner. These positive relationship processes increase personal as well as relationship well-being (Algoe, Gable, \& Maisel, 2010; Wood, Maltby, Gillett, Linley, \& Joseph, 2008). Moreover, they generate positive emotions and therefore have the potential to increase psychological resources (e.g., Fredrickson, Mancuso, Branigan, \& Tugade, 2000; Tice, Baumeister, Shmueli, \& Muraven, 2007). This is argued to increase adaptation to stressful events like the transition to parenthood.

Perceived partner responsiveness is defined as the feeling that the partner is understanding, caring, and validates the self (Reis, Clark, \& Holmes, 2004). By being responsive, the partner communicates that he or she addresses the person's needs and wishes and supports the person's actions; in other words, the partner attends to and reacts supportively to fundamental, core-defining features of the self. Perceived partner responsiveness promotes relationship quality (Canevello \& Crocker, 2010) and can help partners in dealing with stressful events by increasing the effectiveness of spousal support (Maisel \& Gable, 2009). Although spousal 
support across the transition to parenthood is related to lower emotional distress in mothers and infants and an increase in marital satisfaction for both men and women (Simpson, Rholes, Campbell, Tran, \& Wilson, 2003; Stapleton et al., 2012), it is also often unrelated to positive outcomes or even associated with negative effects (e.g., Bolger, Zuckerman, \& Kessler, 2000). Previous research shows that supportive behavior has a positive impact on the well-being of the recipient when the partner is perceived as being responsive toward the recipient (Algoe \& Stanton, 2012; Kubacka, Finkenauer, Rusbult, \& Keijsers, 2011; Maisel $\&$ Gable, 2009). Perceived partner responsiveness is therefore hypothesized to increase adaptation to first-time parenthood.

Another positive relationship process that can be regarded as a resource is felt gratitude. Gratitude is a positive emotion that recipients feel toward their partner when they perceive the efforts of their partner as valuable and deliberate (Kubacka et al., 2011). It strengthens relationships by promoting prosocial behavior from the partner (Emmons \& McCullough, 2004). Positive emotions such as felt gratitude have numerous beneficial effects, among them reducing anxiety-induced cardiovascular reactivity (Fredrickson et al., 2000), improving self-regulation (Tice et al., 2007), and increasing psychological resilience (Fredrickson \& Joiner, 2002). Gratitude has been found to predict lower levels of stress and depression (Wood et al., 2008) and has consistently been found to increase relationship quality (e.g., Algoe, Haidt, \& Gable, 2008; Algoe et al., 2010). Feeling grateful toward the partner could therefore be seen as a psychological resource that can improve adaptation, protect against stress and depression, and improve relationship quality across the transition to parenthood. We therefore hypothesize that felt gratitude toward the partner prior to pregnancy will predict better perceived adaptation to parenthood.

Finally, we consider felt trust a relationship resource that enhances adaptation to the transition to parenthood. Trust has often been identified as one of the most desirable qualities in a relationship and is seen as fundamental for relationship satisfaction (Rempel, Holmes, \&
Zanna, 1985). According to Rempel and colleagues (1985), partner-specific trust is based on three components: predictability (i.e., a partner's stability and consistency), dependability (i.e., a partner's honesty and dependability), and faith (i.e., the belief that the partner will continue to show empathy and consideration in the future). We believe that the relationship changes and the potential stressors that accompany the transition to parenthood make partner-specific trust especially important. On the one hand, trust has been found to increase due to stress, a reaction that is theorized to function as a coping mechanism by overcoming worries about the future of the relationship (Koranyi \& Rothermund, 2012). In addition, across the transition to parenthood, partners become increasingly interdependent as they have to rely on one another not only as partners but also as parents. This increased interdependence is theorized to foster trust (Simpson, 2007). On the other hand, when first-time parents trust their partner and know they can rely on their partner, now and in the future, they are better equipped to deal with the challenges and insecurities of the transition to parenthood, thus increasing adaptation. This study will therefore test the prediction that partner-specific trust increases perceived adaptation to parenthood.

There are theoretical and empirical reasons for expecting perceived responsiveness, felt gratitude, and felt trust to be related to one another and to relationship quality. For example, gratitude and perceived responsiveness have been found to increase each another in a reciprocal relationship (Kubacka et al., 2011; Wood et al., 2008). Over time, the reciprocal pattern between perceived responsiveness and gratitude is theorized to build trust as individuals learn that their partners are responsive to their needs and exhibit prorelationship behavior (Bartlett \& DeSteno, 2006). Partner-specific trust is positively related to relationship quality (Finkenauer, Kerkhof, Righetti, \& Branje, 2009). Trust also increases commitment, leading to greater willingness to exhibit prorelationship behavior (Wieselquist, Rusbult, Foster, \& Agnew, 1999), which could in turn increase perceived responsiveness and gratitude. Furthermore, it is theoretically 
possible that perceived responsiveness, gratitude, and trust are in fact proxies of helpful and positive behavior exhibited by the partner and that the effects found on adaptation to parenthood are driven by positive partner behaviors. If this is the case, perceived responsiveness is likely the most direct measure of the partners' positive behavior.

The contribution of our research is that we study concrete positive relationship processes instead of more general measures of relationship quality that have been the focus of most research on the transition to parenthood. As little is known about the effects on adaptation to parenthood, the current research will first examine the effect of these constructs independently to gain more insight into the effects of prepregnancy levels and changes over time, as will be discussed next. We will however test additional models with control variables, such as relationship quality, to examine alternative explanations.

\section{Models of relationship change}

A matter of contention in the relationship literature is the question of how relationships change over time and, particularly, whether it is possible to predict marital stability and distress at the beginning of marriage or whether marital distress is predicted by changes over time. Three models have been developed in an attempt to predict general marital distress and can be applied to the transition to parenthood (see also Kluwer \& Johnson, 2007): the disillusionment model, the emergent distress model, and the enduring dynamics model (Huston, Caughlin, Houts, Smith, \& George, 2001). Both the disillusionment model and the emergent distress model assume that newlyweds have an idealized view of their partner at the beginning of their marriage. Marital distress is caused by increases in negative feelings and behaviors over time (emergent distress) or decreases in positive feelings and behaviors over time (disillusionment). By contrast, the enduring dynamics model proposes that relationship problems that eventually lead to marital distress are already present at the beginning of marriage (Karney \& Bradbury, 1995).
In support of the enduring dynamics model, a number of studies found that factors measured during pregnancy predicted lower personal and relational adjustment after childbirth. Examples are greater conflict frequency (Kluwer \& Johnson, 2007), insecure attachment (Alexander, Feeney, Hohaus, \& Noller, 2001), perceiving partner anger (Simpson et al., 2003), the father's negativity toward the mother (Shapiro, Gottman, \& Carrère, 2000), and lower self-esteem (Belsky \& Rovine, 1990). In support of the disillusionment model, Howard and Brooks-Gunn (2009) found that the majority of couples started out supportive after childbirth, but it was the change in support across the first year and not the level of support during pregnancy that predicted separation. However, like most studies on the transition to parenthood literature, these studies did not include prepregnancy measurements. We therefore have limited knowledge of the predictive power of couples' strengths and weaknesses present before pregnancy. There may be a so-called transition to pregnancy effect, with changes in personal and relationship well-being already taking place during pregnancy (Lawrence, Rothman, Cobb, Rothman, \& Bradbury, 2008). We will therefore compare whether positive relationship processes prior to pregnancy versus changes across the transition to parenthood are related to perceived adaptation. Because we will focus only on positive and not on negative relationship processes, this study does not test the emergent distress model.

\section{This study}

This study aims to investigate the role of positive relationship processes in how new parents adapt to parenthood. It focuses on the actor perceiving responsiveness from the partner, the actor feeling gratitude for the partner, and the actor trusting the partner. According to the literature, these positive experiences will increase the actor's resources and thus adaptation to a challenging transition. We hypothesize that both higher initial levels prior to pregnancy and stronger increases over time in perceived responsiveness, felt gratitude, and felt trust will predict better perceived adaptation to parenthood. 
This study will add to the existing literature on the transition to parenthood in several ways. First, our research contributes to the existing literature by measuring perceived adaptation to parenthood instead of using other markers of well-being to deduce adaptation. Our Adaptation to Parenthood Scale measures several aspects of adaptation, namely, parental responsibilities and marital changes, parental joys, satisfaction with changes since childbirth, and problems common for new parents. This broad measure of adaptation allows us to gain a more complete and nuanced insight in parental well-being after childbirth. Adaptation in this case reflects the parents' own perceived adaptation, making self-reports an appropriate method to measure well-being after childbirth despite the fact that this method has limitations, such as the possible influence of social desirability.

Second, in contrast to most previous research on the transition to parenthood, we investigate the role of positive relationship experiences in order to identify factors that act as resources and increase coping and adaptation, as argued by the VSA model (Karney \& Bradbury, 1995). Such factors can be used in pregnancy courses, for example, to educate couples about what could help them ease their adaptation to parenthood. Third, we will compare the predictive strength of the initial levels of these positive relationship experiences prior to pregnancy versus changes over time. The inclusion of prepregnancy measurements is rare in research on the transition to parenthood and allows for a stronger test of the hypothesis that relationship processes present prior to the transition to parenthood predict adaptation.

Finally, we add to previous research by including both partners in our analyses. Even though nearly all theories on close relationships recognize that partners have reciprocal influence on each other (Campbell \& Kashy, 2002), studies on the transition to parenthood generally do not include both partners in the same analyses. The behavior, personality, emotions, and cognitions of one partner can affect the personal as well as relationship well-being of the other partner (Campbell \& Kashy, 2002). In this study, we will compare the effects of a person's positive relationship experiences on his or her own perceived adaptation to parenthood as well as on his or her partner's perceived adaptation. In addition, this enables us to test whether gender differences occur in the associations between positive relationship processes and perceived adaptation to parenthood or whether the models are the same for fathers and mothers. Although many studies have found gender differences in changes across the transition to parenthood, with women generally showing stronger declines in relationship quality (Twenge et al., 2003), prior research does not provide reason to expect gender differences in the associations between positive relationship processes and perceived adaptation to parenthood.

\section{Method}

\section{Participants and procedure}

We used data from the Marriage and Wellbeing Survey that were collected between 2006 and 2010 from 199 newlywed Dutch couples as part of a larger study (Finkenauer et al., 2009). Couples were recruited within 2 months after their wedding day and interviewed five times, at approximately 1 -year intervals. Of the couples recruited, 132 became parents during the course of the data collection. However, 23 of these couples had their first child before Time 2 , so we cannot rule out that they were pregnant at Time 1. Because that means that no prepregnancy data were available for these couples, they were excluded from this study. Couples that did not have children during the course of this study were also excluded as perceived adaptation to parenthood was measured among parents only. The final sample thus consisted of 109 couples who became pregnant during the course of the data collection.

The mean age of the fathers was 31.82 years $(S D=3.51)$, and the mean age of the mothers was 28.78 years $(S D=4.07)$ at Time 1 . Couples had been romantically involved for 5.85 years $(S D=2.85)$ on average. Nearly all couples were of Dutch nationality (97.2\%). Of the fathers, $30.5 \%$ had completed high school or secondary vocational education, and $61.1 \%$ had completed higher vocational education or 
university. Of the mothers, $25.9 \%$ had completed high school or secondary vocational education, and $67.9 \%$ had a higher education. At Time 1, 72.5\% of the men worked 33-40 hr a week, $11.1 \%$ worked less than $33 \mathrm{hr}$ a week, and $15.7 \%$ worked more than $40 \mathrm{hr}$ a week. Of the women, $32.1 \%$ worked between 25 and $32 \mathrm{hr}$ a week, $49.5 \%$ worked $33-40 \mathrm{hr}$, $11.2 \%$ worked less than $25 \mathrm{hr}$ a week, and $5.5 \%$ worked more than $40 \mathrm{hr}$.

Participants were recruited via the municipalities in which they got married. An average of 1 month after their wedding day, each couple received a letter that described the study as a longitudinal examination of the factors that contribute to marital and individual well-being. When both partners were interested in participating in the study, they provided their names and telephone number on a prepaid return postcard. Inclusion criteria were that this was the couple's first marriage, that couples had no children in this marriage or from previous relationships, and that partners were between 25 and 40 years old. Of all the couples who fulfilled the criteria, 19\% agreed to participate in the study. This response rate is similar to studies recruiting participants from public records in the United States (e.g., Kurdek, 1991). At each data collection session, both members of the couple separately filled out a questionnaire at home in the presence of a trained interviewer. The questionnaire took about 90 min to complete. Partners were instructed not to discuss the questions or answers with each other during data collection. Couples received 15 euros and a small gift (e.g., a book, a pen set) after they completed their questionnaires.

There was a relatively low attrition rate in this longitudinal study. All couples participated until at least Time 3; 11 couples dropped out before Time 4 and an additional 10 couples before Time 5 , leaving 88 couples who participated in all five waves $(80.7 \%$ of the initial couples from Time 1). An analysis of variance (ANOVA) showed that there were no differences in any of the main variables between those couples who completed all five waves and those who dropped out. A total of 64 couples became parents between Times 2 and $3(48.5 \%), 29$ couples $(22.0 \%)$ between Times
3 and 4 , and 16 couples between Times 4 and $5(12.1 \%)$, resulting in three birth cohorts. All the pregnancies were planned. An ANOVA revealed that the birth cohorts did not differ on any of the main measures or demographic variables at Time 1 . All three cohorts were therefore included in the same analyses.

\section{Measures}

\section{Perceived responsiveness}

Perceived responsiveness was measured using 18 items adapted from Reis's Perceived Responsiveness Scale (Kubacka et al., 2011). This measure assessed perceptions of the partner as being caring, validating, and understanding. Example items are "My partner responds to my needs" (tapping caring), "My partner appreciates my skills and opinions" (tapping validating), and "My partner understands me" (tapping understanding). Answers were rated on a 5 -point scale $(1=$ do not agree at all to $5=$ agree completely). Cronbach's $\alpha \mathrm{s}$ ranged between .91 and .96 for men and .93 and .97 for women across waves.

\section{Gratitude}

Felt gratitude was measured with four questions adapted from the six-item Gratitude Scale (GQ-6; McCullough, Emmons, \& Tsang, 2002) to measure partner-specific gratitude (Kubacka et al., 2011). The GQ-6 showed good convergent and discriminant validity (McCullough et al., 2002). The items were "I have a lot for which I am grateful to my partner," "If I were to list everything for which I am grateful to my partner, it would be a very long list," "I appreciate my partner more the longer we are together," and "A long time can pass before I feel gratitude towards my partner." This last item was reverse scored. Answers were rated on a 5-point scale $(1=d o$ not agree at all to 5=agree completely). Cronbach's $\alpha$ s ranged between .62 and .68 for men and .61 and .69 for women across waves, except for Time 5, where women's $\alpha$ was .81 .

\section{Trust}

Felt trust was measured with 12 items adapted from the Partner-Specific Trust Scale 
developed by Rempel and colleagues (1985). The scale assesses three aspects of trust: predictability, or how stable and consistent a partner is (e.g., "My partner is very unpredictable. I never know how he/she is going to react"; reversed); dependability, a dispositional evaluation of a partner's honesty and reliability (e.g., "My partner is very dependable, especially when it comes to things that are important to me"); and faith, the belief that a partner will be understanding and caring despite the uncertainty of the future (e.g., "I know my partner will always be ready and willing to offer me strength and support"). Answers were rated on a 5-point scale $(1=d o$ not agree at all to 5=agree completely). Cronbach's $\alpha$ s ranged between .79 and .88 for men and .82 and .85 for women across waves.

\section{Perceived adaptation to parenthood}

How well parents felt they had adapted to parenthood was measured with 25 items adapted from the Transition Difficulty Scale (Steffensmeier, 1982), measured at Time 5. Our version of the scale consisted of four subscales: Concerns, Parental Gratification, Satisfaction with Changes, and Problems. The Concerns subscale consisted of 7 items measuring concerns about parental responsibilities (e.g., "I worry whether I am a good parent") and marital changes (e.g., "I worry that my partner and I do not spend enough time together" and "I worry about our sex life"). These items were reverse scored. The Parental Gratification subscale consisted of 5 items measuring personal well-being (e.g., "Since the birth of our child[ren] I feel happy"). The Satisfaction with Changes subscale consisted of 5 items measuring satisfaction with changes since childbirth. For example, participants were asked, "How satisfied are you with the changes since the birth of your child(ren) concerning the following: not being able to go out." The Problems subscale consisted of 2 items, "Since the birth of our child I suffer from lack of sleep" and "Since the birth of our child I am often interrupted while I am in the middle of something." These items were reverse scored. All answers were rated on 5-point scales. A factor analysis showed that the best fit was one factor that explained $31.3 \%$ of the variance. All items were therefore averaged into one scale with Cronbach's $\alpha$ s of .89 for men and .88 for women. A higher mean score indicated greater perceived adaptation.

\section{Relationship quality}

Relationship quality (control variable) was measured using the Dyadic Adjustment Scale (DAS; Spanier, 1976). The scale consists of 32 items divided over four subscales: Dyadic Satisfaction, Dyadic Cohesion, Dyadic Consensus, and Affectional Expression. Example items are "How often do you think that things are going well between you and your partner?" and "How often do you kiss your partner?" The majority of the items were rated on a 6-point or a 5-point scale. A higher mean score indicated greater relationship quality. Cronbach's $\alpha$ s were .85 for men and .87 women at Time 1 .

\section{Analyses}

To test our hypotheses, we applied latent growth curve modeling based on the principles of the actor-partner interdependence model (APIM; Kashy \& Kenny, 2000). APIMs include both partners, which allowed for the simultaneous estimation of the effect of a person's positive relationship processes on his or her own adaptation to parenthood (the actor effect) as well as on his or her partner's adaptation (the partner effect). The APIM is preferable to traditional techniques because of the interdependence between partners' observations and because of our hypothesis regarding partner effects. A latent growth model captures linear developmental change in two latent growth factors: The average baseline level at Time 1 is represented by an intercept, and the average rate of linear change over time is represented by a linear slope. Ideally, we would have liked to differentiate between change over time that occurred before and after childbirth. We therefore extended the model with two additional growth factors: an intercept and slope after childbirth. However, these models did not have a good fit, most likely due to the fact that the three birth cohorts were too small to analyze separately. Models were therefore estimated with one 


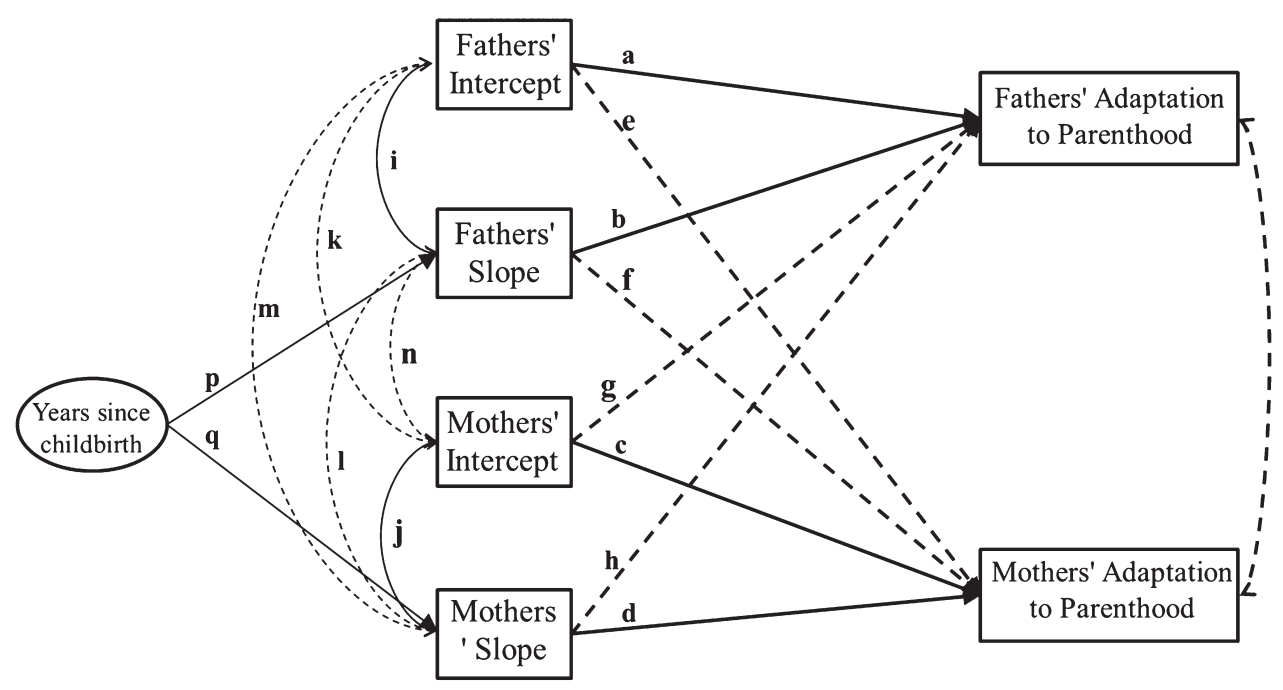

Figure 1. Full-tested path model prior to the constraining and removal of paths.

intercept, corresponding to the average level of perceived responsiveness, gratitude, and trust before pregnancy, and one slope, representing the changes of these positive relationship processes across time. To take into account the fact that childbirth occurred at different time points, the amount of time since childbirth was added as a covariate in all models and used to correct the slopes. Adaptation was also corrected for time passed since childbirth as adaptation may also increase in the years after the birth of the first child, and adaptation of the partners was allowed to correlate.

A baseline model was first tested with all possible parameters included. This model is illustrated in Figure 1. The unbroken straight lines represent actor effects; the dotted straight lines represent partner effects. Path coefficients were constrained to be equal for men and women when this led to better model fit, which indicates that there is no significant gender difference based on the chi-square difference test (Peugh, DiLillo, \& Panuzio, 2013). Elements of the model that were not significant were removed for parsimony in a process of backward elimination if this removal led to an improved model fit. Backward deletion is commonly used to reduce problems associated with multicollinearity (Pedhazur, 1982). The final models, after parameters were constrained or removed, are illustrated in Figures 2-4.
Models were estimated using version 7.4 of the statistical program Mplus (Muthén \& Muthén, 1998-2015), which also allowed us to include all available data using a full information maximum likelihood procedure. Model fit was assessed using the comparative fit index (CFI) and root mean square error of approximation (RMSEA). In general, a value higher than .90 for the CFI and lower than .08 for the RMSEA is considered an acceptable model fit (Byrne \& Crombie, 2003). Additional models with control variables were also tested in order to examine the likelihood of alternative interpretations for the results. These additional models are not nested, and we therefore also report the Akaike information criterion (AIC) to make model comparison possible. Given a set of models, the preferred model is the one with the lowest AIC value. In other words, a lower AIC value indicates better model fit (Akaike, 1973). The input files of all the models are available from the first author upon request.

\section{Results}

Table 1 presents the within-person correlations between the main variables (above the diagonal for women and below the diagonal for men) and the intercorrelations between members of the dyad for each variable (in bold on the diagonal). Table 2 presents the means and 
Table 1. Intercorrelations between all assessed variables at Time 1

\begin{tabular}{|c|c|c|c|c|}
\hline Variables & 1 & 2 & 3 & 4 \\
\hline $\begin{array}{l}\text { 1. Responsive- } \\
\text { ness }\end{array}$ & .16 & $.44 *$ & $.45^{* *}$ & $.68 * *$ \\
\hline 2. Gratitude & $.41 * *$ & -.01 & $.34 * *$ & $.47 * *$ \\
\hline 3. Trust & $.70 * *$ & $.50 * *$ & $.26 *$ & $.55 * *$ \\
\hline $\begin{array}{l}\text { 4. Relationship } \\
\text { quality }\end{array}$ & $.46 * *$ & $.41 * *$ & $.54 * *$ & $.40 * *$ \\
\hline
\end{tabular}

Note. Within-person intercorrelations for women are presented above the diagonal, and within-person intercorrelations for men are presented below the diagonal. Intercorrelations between dyad members (husband and wife) are presented in bold on the diagonal.

${ }^{*} p<.05 . * * p<.01$

standard deviations of the main variables at all time points. The analysis of the growth curve models was conducted in two steps. In Step 1 , we examined the intercept ( $I$; level before pregnancy) and slope ( $S$; change over time) of the positive relationship processes across the transition to parenthood, and how partners influenced each other's intercept and slope. Note that the intercept may differ slightly from the mean at Time 1 because the intercept of fathers and mothers is constrained to be equal in the model when there is no significant gender difference. In the second step, we tested our hypotheses by regressing the score of the Perceived Adaptation to Parenthood Scale on the four latent growth parameters (the intercept and slope of fathers and the intercept and slope of mothers). This allowed us to test for actor effects as well as partner effects of positive relationship processes on adaption to parenthood. We report the unstandardized regression coefficients $(B)$ of the final models in the text. The final models with the unstandardized coefficients $(B)$ as well as the standardized coefficients $(\beta$; in parentheses) are presented in Figures 2-4. Standardized coefficients may differ for husbands and wives even when a path has been constrained to be equal because the coefficients are standardized using the standard deviations, which may differ for husbands and wives. The intercept and slope associations between and within partners are also presented in the figures. These correlations are not discussed because they are unrelated to the hypotheses of this study.

\section{Perceived responsiveness}

Both fathers and mothers, on average, perceived their partners as being very responsive prior to pregnancy $(I=4.23, \quad p<.001)$. Mothers experienced a small but significant decrease in perceived responsiveness over time $(S=-.02, p=.018)$. Fathers did not report a significant change in perceived responsiveness over time $(S=.03, p=.220)$. The final model produced fit indices of $\mathrm{CFI}=.964$, $\mathrm{AIC}=912.168, \quad \mathrm{RMSEA}=.058 ; \quad 90 \% \quad \mathrm{CI}$ $[.025, .085]$. There were no significant gender differences; all effects in the final model are therefore the same for mothers and fathers (see Figure 2). There were significant actor effects. As hypothesized, fathers and mothers

Table 2. Means (and standard deviations in parentheses) of the main variables at every time point

\begin{tabular}{lccccc}
\hline \hline Time point & 1 & 2 & 3 & 4 & 5 \\
\hline Men & & & & & \\
Responsiveness & $4.25(.40)$ & $4.25(.42)$ & $4.21(.42)$ & $4.20(.40)$ & $4.24(.48)$ \\
Gratitude & $4.05(.50)$ & $4.15(.52)$ & $4.08(.49)$ & $4.13(.46)$ & $4.13(.53)$ \\
Trust & $4.24(.42)$ & $4.24(.42)$ & $4.23(.47)$ & $4.24(.46)$ & $4.26(.46)$ \\
Women & & & & & \\
Responsiveness & $4.23(.42)$ & $4.22(.43)$ & $4.15(.43)$ & $4.15(.47)$ & $4.18(.49)$ \\
Gratitude & $4.08(.50)$ & $4.13(.51)$ & $4.08(.56)$ & $4.12(.53)$ & $4.10(.61)$ \\
Trust & $4.21(.43)$ & $4.24(.44)$ & $4.25(.47)$ & $4.18(.49)$ & $4.23(.48)$ \\
\hline \hline
\end{tabular}




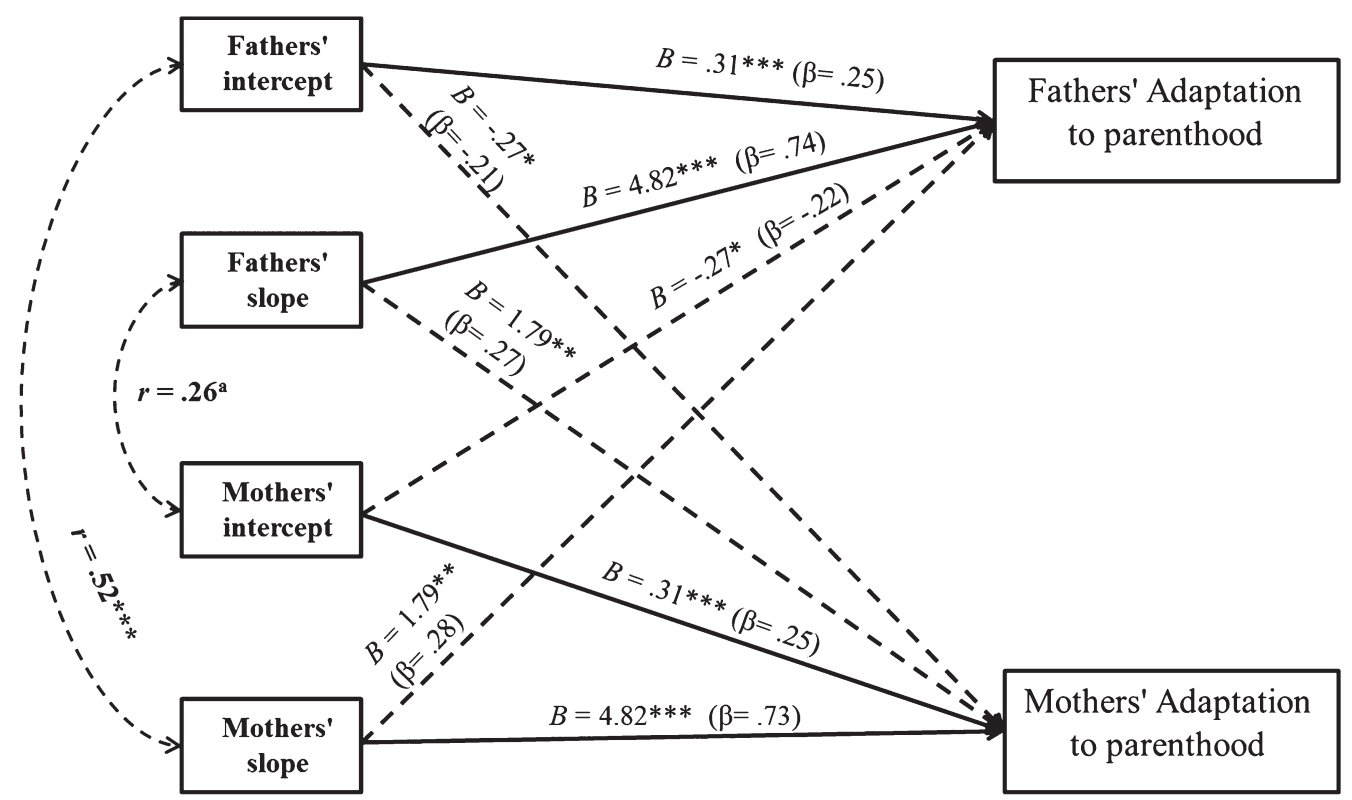

Figure 2. Actor and partner effects of perceived responsiveness on adaptation to parenthood using the intercept (i.e., average level prior to pregnancy) and slope (i.e., change over time). Estimates are unstandardized regression coefficients $(B)$ with standardized coefficients $(\beta)$ in parentheses. Unbroken straight lines represent actor effects, dotted straight lines represent partner effects, and dotted curved lines represent correlations $(r)$ between/within partners' slope and/or intercept.

${ }^{a} p<.10 . * p<.05 . * * p<.01 . * * * p<.001$.

who reported higher perceived responsiveness before pregnancy reported a better adaptation to parenthood (unstandardized $B=.31$, $p=.003$ ). Parents whose perceived partner responsiveness increased across the transition to parenthood also reported better adaptation, and this effect was larger than the effect of initial levels of perceived responsiveness before pregnancy $(B=4.82, p<.001)$. Change over time was thus a stronger predictor of perceived adaptation than initial levels of perceived responsiveness prior to pregnancy.

There were also significant partner effects. Contrary to expectations, fathers' and mothers' level of perceived partner responsiveness prior to pregnancy negatively predicted their partner's adaptation to parenthood $(B=-.27$, $p=.017)$. The higher the initial level of perceived partner responsiveness, the lower their partner's adaptation. However, as expected, an increase in the father's and the mother's perceived responsiveness over time was positively associated with their partner's adaptation $(B=1.79, p=.001)$. Time since childbirth was unrelated to change in perceived responsiveness over time. To further explore why the average level of perceived responsiveness prior to pregnancy had a negative effect on the partner's perceived adaptation, we ran a median split analysis. The analysis showed that this negative partner effect was only present when partners had above-average initial levels of perceived responsiveness. A possible explanation for this finding will be discussed in the Discussion.

\section{Gratitude}

On average, fathers and mothers felt grateful toward their partner prior to pregnancy $(I=4.09, p<.001)$, and their level of gratitude did not change over time $(S=0.01, p=.40)$. There were no differences between fathers and mothers in the intercept and slope. The 


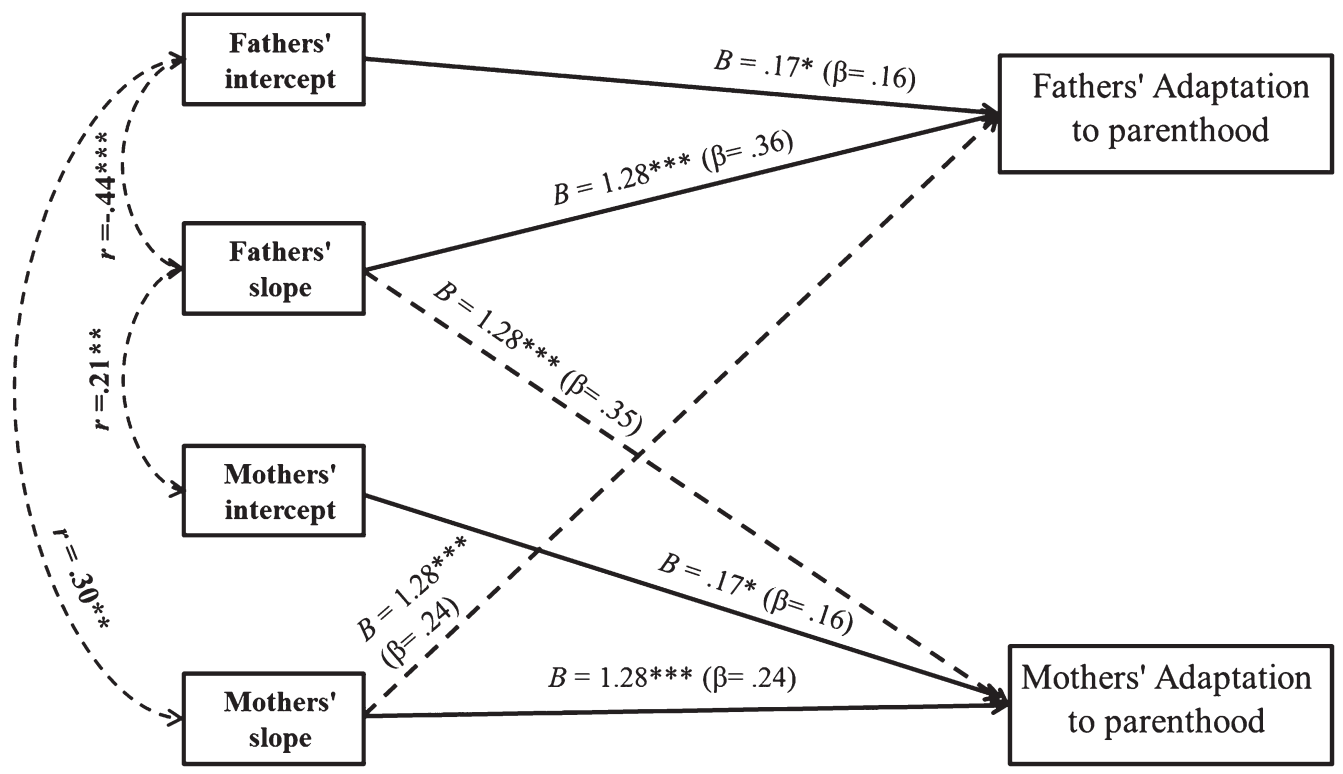

Figure 3. Actor and partner effects of gratitude on adaptation to parenthood using the intercept (i.e., average level prior to pregnancy) and slope (i.e., change over time). Estimates are unstandardized regression coefficients $(B)$ with standardized coefficients $(\beta)$ in parentheses. Unbroken straight lines represent actor effects, dotted straight lines represent partner effects, and dotted curved lines represent correlations $(r)$ between/within partners' slope and/or intercept.

$* p<.05 . * * p<.01 . * * * p<.001$.

final model produced fit indices of $\mathrm{CFI}=.982$, $\mathrm{AIC}=1309.966, \quad \mathrm{RMSEA}=.035 ; 90 \%$ CI $[.000, .069]$. There were no significant gender differences in the final model. There were significant actor effects (see Figure 3). As expected, fathers' and mothers' gratitude toward their partner before pregnancy positively predicted their own adaptation $(B=.17$, $p=.043)$, and an increase in gratitude across the transition to parenthood positively predicted adaptation $(B=1.28, p<.001)$. Both fathers' and mothers' perceived adaptation to parenthood was most strongly influenced by their own change in felt gratitude over time. The standardized effects (see the $\beta$ s in Figure 3) show that this effect was stronger for fathers than for mothers. Fathers' and mothers' adaptation was not predicted by their partner's gratitude before childbirth but was positively associated with their partner's increase in gratitude over time $(B=1.28$, $p<.001)$. Thus, parents whose partner felt more grateful toward them across the transition to parenthood reported better adaptation.
This partner effect did not differ significantly from the actor effect of the slope of gratitude on adaptation. Thus, the change in their own felt gratitude and the change in their partner's felt gratitude were equally associated with their own adaptation. Time since childbirth was unrelated to the slopes of either fathers or mothers, suggesting that the transition to parenthood did not affect the level of gratitude partners felt for one another.

\section{Trust}

On average, fathers and mothers felt a high level of trust for their partner $(I=4.24$, $p<.001)$. Fathers experienced an increase in trust across time $(S=.06, p=.03)$, whereas mothers reported no change in trust over time $(S=.03, p=.46)$. The final model of trust produced fit indices of $\mathrm{CFI}=.986, \mathrm{AIC}=$ 662.314, and RMSEA $=.039 ; 90 \%$ CI $[.000, .072]$. The final model showed some significant gender differences. There were significant actor effects (see Figure 4). 


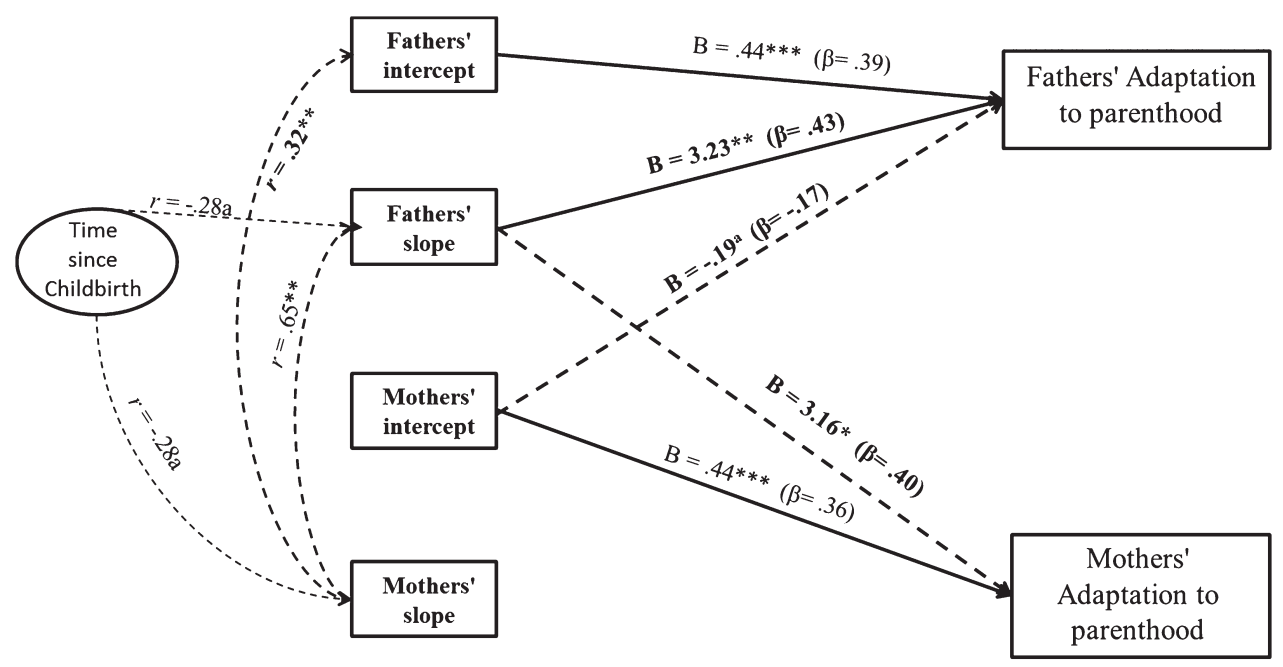

Figure 4. Actor and partner effects of trust on adaptation to parenthood using the intercept (i.e., average level prior to pregnancy) and slope (i.e., change over time). Estimates are unstandardized regression coefficients $(B)$ with standardized coefficients $(\beta)$ in parentheses and effects that interact with gender in bold. Unbroken straight lines represent actor effects, dotted straight lines represent partner effects, and dotted curved lines represent correlations $(r)$ between/within partners' slope and/or intercept and with time since childbirth.

${ }^{a} p<.10 . * p<.05 . * * p<.01 . * * * p<.001$.

Confirming our expectations, trusting one's partner prior to pregnancy predicted higher perceived adaptation to parenthood for both fathers and mothers $(B=.44, p<.001)$. An increase in trust across the transition to parenthood was positively related to perceived adaptation for fathers $(B=3.23, p=.011)$ but not for mothers. The partner effects showed that an increase in their partner's trust across time predicted higher perceived adaptation for mothers $(B=3.16, p=.023)$ but not for fathers. Although the negative effect of the mothers' trust prior to pregnancy on their partner's perceived adaptation increased model fit and was therefore left in the model, it was not significant $(B=-.19, p=.099)$. In addition, there was a marginally significant negative correlation between time since childbirth and fathers' and mothers' slope $(r=-.28$, $p=.06$ ), suggesting that felt trust decreased after childbirth.

In sum, the results largely support our expectation that prepregnancy perceived responsiveness, gratitude, and trust and changes in these constructs across the transition to parenthood predict one's own and partner's perceived adaptation to parenthood up to 4 years later. For perceived responsiveness, all the actor and partner effects were significant, although partner's prepregnancy perceived responsiveness was negatively related to adaptation, which was not expected. Both actor and partner prepregnancy gratitude and change in gratitude over time positively predicted adaptation, with the exception of the partner's prepregnancy gratitude, which was not significant. Fathers' prepregnancy trust and change in trust across the transition to parenthood positively predicted their own adaptation; their partner's trust, however, did not. Mothers' prepregnancy trust and their partner's increase in trust over time positively predicted their adaptation to parenthood.

\section{Additional analyses}

As discussed earlier, there are theoretical and empirical reasons for expecting perceived responsiveness, gratitude, and trust to be related to relationship quality. We therefore tested additional models with relationship 
quality at Time 1 as a control variable in order to test the unique effects of responsiveness, gratitude, and trust on perceived adaptation to parenthood independent of relationship quality. In addition, we tested models of gratitude and trust while controlling for perceived responsiveness at Time 1 to test whether a partner's positive actions, as most closely measured by perceived responsiveness, can explain the effects found in the main analyses. Control variables were added to the model by controlling the intercepts, slopes, and the outcome variable (i.e., perceived adaptation) for the control variable. Any effects that remain significant are most likely not due to the influence of the control variable. The effects that changed compared to the original model are discussed below. All the effects of the models of the additional analyses can be found in Table 3.

\section{Controlling for relationship quality}

The model of perceived responsiveness controlled for relationship quality at Time 1 produced fit indices of $\mathrm{CFI}=.954$, $\mathrm{AIC}=1957.772$, and RMSEA $=.066 ; 90 \% \mathrm{CI}$ $[.039, .091]$. CFI and RMSEA were lower and AIC was higher than in the original model, indicating a lower fit than the original model. Mothers' perceived responsiveness prior to pregnancy no longer predicted their own adaptation when controlling for relationship quality at Time 1 . The negative effect of fathers' perceived responsiveness at Time 1 on mothers' adaptation also disappeared. The positive effect of an increase in perceived responsiveness over time on one's own adaptation became larger for fathers. The model for gratitude controlled for relationship quality at Time 1 produced fit indices of $\mathrm{CFI}=.983$, $\mathrm{AIC}=2596.512$, and RMSEA $=.030 ; 90 \% \mathrm{CI}$ [.000, .063]. CFI and RMSEA were slightly higher than for the original model, indicating better fit, but AIC was also higher, indicating lower fit. The actor effect of gratitude prior to pregnancy on one's own adaptation disappeared for both fathers and mothers. The positive effect of an increase in gratitude over time on one's own adaptation was stronger for mothers. The model for trust controlled for relationship quality at Time 1 produced fit

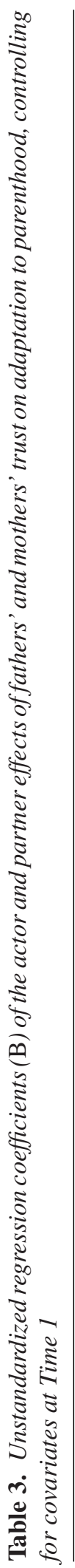


indices of $\mathrm{CFI}=.991$, $\mathrm{AIC}=2005.444$, and RMSEA $=.029 ; 90 \%$ CI $[.000, .063]$. CFI and RMSEA were slightly higher than for the original model, but AIC was also higher, indicating lower fit. The actor effect of mothers' trust prior to pregnancy on one's own adaptation disappeared. The positive effect of an increase in trust over time on one's own adaptation became larger for both parents.

\section{Controlling for perceived responsiveness}

The model for gratitude controlled for perceived responsiveness at Time 1 produced fit indices of $\mathrm{CFI}=.971$, $\mathrm{AIC}=1349.775$, and RMSEA $=.041 ; 90 \%$ CI [.000, .070], a lower fit than the original model. The actor effect of gratitude prior to pregnancy on one's own adaptation disappeared for both parents. The positive effect of an increase in gratitude over time on one's own adaptation was stronger for mothers (see Table 3). The model for trust controlled for perceived responsiveness at Time 1 produced fit indices of $\mathrm{CFI}=.971$, $\mathrm{AIC}=1349.775$, and $\mathrm{RMSEA}=.041 ; 90 \% \mathrm{CI}$ [.000, .063]. CFI and RMSEA were slightly higher than for the original model, but AIC was also higher, indicating lower fit. The actor effect of trust prior to pregnancy on one's own adaptation disappeared for mothers. The positive effect of an increase in trust over time on one's own adaptation became larger for fathers. The negative effect of mothers' trust prior to pregnancy on fathers' adaptation, which was not significant in the original model, became significant.

In sum, the models with relationship quality or perceived responsiveness added as a control variable showed similar results, and none of the models had a better fit as indicated by the AIC. Some actor effects of the main variables prior to pregnancy were no longer significant, suggesting that these effects may have been due to initial relationship quality or perceived responsiveness. However, some effects of an increase in the main variable over time were larger than in the original models.

\section{Power analyses}

Because we used a relatively small sample, we assessed the power of our study with a Monte
Carlo simulation using the parameter estimates from our real data analysis. We found that the power of the significant effects of the intercepts and slopes on one's own adaptation ranged between .45 and .94 . The power of the effect of the intercepts on the partner's adaptation was generally lower, ranging between .15 and .75 . Because power is the probability to correctly reject the null hypothesis, a significant finding with low power suggests that the effect size in the actual population is larger (Bakan, 1966). Thus, if we should replicate our study with a larger sample, we would expect to find larger effects of the partner's intercepts and slopes on perceived adaptation to parenthood. The power of the nonsignificant effects of the slopes was generally very low, below .10. Although this might indicate that inadequate power is the reason that these effects were not significant, it should be noted that the observed (post hoc) power is a function of the observed $p$ value (Hoenig \& Heisey, 2001). Thus, nonsignificant $p$ values always correspond to low observed power. We also looked at the confidence intervals as the breadth of the confidence interval informs us about how confident we can be of the nonsignificant effects actually being close to zero (Colegrave \& Ruxton, 2003; Hoenig $\&$ Heisey, 2012). This showed that the nonsignificant effect of mothers' trust prior to pregnancy on fathers' adaptation was indeed close to zero $(B=-.178, p=.099 ; 95 \% \mathrm{CI}$ $[-.372, .015])$. The effect of mothers' change in trust on fathers' adaptation to parenthood may be insignificant due to low power as the confidence interval showed a wide range with an upper limit quite a bit higher than zero $(B=-.910, p=.57 ; 95 \%$ CI $[-3.536,1.717])$. The same was true for the effect of mothers' change in trust on their own adaptation $(B=.290, p=.86 ; 95 \%$ CI $[-2.403,2.983])$. For the insignificant effect of fathers' change in trust on mothers' adaptation, the range of confidence interval was much smaller, but the upper range is still above zero $(B=-.016$, $p=.91 ; 95 \%$ CI $[-.237, .205])$. The only effect in the model of gratitude that was not significant was that of the partners' gratitude on adaptation. The range of confidence interval for this effect was quite small, although the upper range is above zero $(B=-.044, p=.65$; 
$95 \%$ CI $[-.200, .113])$. Therefore, low power seems to be an issue mainly for the nonsignificant effects of mothers' change in trust over time.

\section{Discussion}

The purpose of this study was to explore the role of positive relationship processesperceived responsiveness, felt gratitude, and felt trust-on the perceived adaptation to first-time parenthood. We hypothesized that both high initial levels of positive relationship processes before pregnancy and increases across the transition to parenthood would predict better adaptation to parenthood. In addition, we expected that partners' reports of positive processes would influence each other's perceived adaptation.

The significant actor effects largely supported our hypotheses. Higher levels of perceived responsiveness, gratitude, and trust before pregnancy predicted higher perceived adaptation to parenthood later on. These results show that it is possible to at least partially predict how well first-time parents will adapt to parenthood based on their level of positive relationship processes before pregnancy. This suggests that positive relationship processes prior to pregnancy act as a resource that can diminish the impact of a stressful event (Karney \& Bradbury, 1995). According to the broaden and build model (Fredrickson, 2001), positive emotions such as gratitude and trust have an adaptive purpose by helping to prepare for future challenges. Indeed, we showed that perceived responsiveness, gratitude, and trust increased the perceived adaptation of first-time parents to the changes and challenges of parenthood. In addition to these findings, changes over time were also, or even more, important in predicting perceived adaptation. Increases (vs. decreases) in positive relationship processes across the transition to parenthood predicted higher (vs. lower) adaptation to parenthood. The partner effects of change over time were in line with this as an increase (vs. decline) in the reported positive relationship processes across time was related to an increase (vs. decrease) in the partner's adaptation to parenthood.
Our findings correspond with Huston and colleagues (2001) who found evidence for both the enduring dynamics and the disillusionment model of relationship change. Thus, above and beyond initial levels of positive relationship processes, experiencing a decrease in positive relationship processes was related to lower perceived adaptation. As the initial levels might serve as a reference point, experiencing a decrease (vs. increase) across time indicates worse (vs. better) adaptation for new parents. Indeed, following Huston and colleagues' argument and based on gain/loss models (Aronson \& Lindner, 1965), realizing that the partner has become less responsive over time might be even more stressful than the fact that the partner is currently not very responsive.

Contrary to our expectations, fathers and mothers whose partner reported higher average levels of prepregnancy perceived responsiveness reported lower adaptation to parenthood later on. Perhaps those who perceive above-average partner responsiveness before pregnancy are actually receiving more support from their partner across the transition to parenthood, which might put a strain on the partner providing the support, thereby decreasing their perceived adaptation. That is, the above-average responsive behavior itself might be demanding for the responsive partner him- or herself across the transition to parenthood. Previous studies have found that supporting can lead to emotional distress for those who provide the support (Lewis \& Manusov, 2009). The resources of the partner in the supporting role might become drained, thereby having a detrimental effect on his or her adaptation to parenthood.

This explanation is of course speculative but suggests an interesting avenue for future research, namely, to investigate the perspective of the partner. The current manuscript focuses on the actor perceiving responsiveness from the partner, the actor feeling gratitude for the partner, and the actor trusting the partner. According to the literature, these positive experiences will increase the actor's resources and thus adaptation. Future research should investigate the effects of being responsive toward one's partner, and of perceiving that one's partner is grateful and trusting toward the self. Being 
responsive might come at a cost, as noted previously, but felt gratitude has also been found to be beneficial for the partner receiving the gratitude as it increases their relationship connectedness and satisfaction (Algoe et al., 2010). In addition, trust has been found to be reciprocated between partners (Larzelere \& Huston, 1980), so perceiving trust from the partner might also enhance adaptation. Feeling that your partner is grateful to you and trusts you may strengthen your sense of self-efficacy and control because you feel that your partner believes in you and feels confident in your judgments and abilities.

We analyzed additional models to test whether a common factor underlying all three positive relationship processes could be driving the effects. Overall, the effects of the main variables did not change to such a degree as to suggest that relationship quality or perceived responsiveness, as a proxy of the partner's positive actions, were in fact driving the results. Some actor effects of the main variables prior to pregnancy were no longer significant, and some effects of an increase in the main variable over time were larger than in the original models. Model fit of these additional models was lower than the original models in all cases as indicated by a higher AIC. We note, however, that this is probably due to the added complexity of the model as the AIC penalizes strongly for complexity of the models. Thus, caution is necessary when drawing conclusions based on these additional analyses. The correlations between perceived responsiveness, gratitude, and trust were on average medium to strong (around .45) but not so strong as to offer strong support for an alternative explanation that these variables in fact measure one underlying construct, such as the partner's positive behaviors. We also note that several studies suggest that one's own enacted responsiveness predicts one's perceptions of the partner's responsiveness better than the partner's own reports of enacted responsiveness, suggesting a projection of one's own responsiveness (e.g., Debrot, Cook, Perrez, \& Horn, 2012; Lemay \& Clark, 2008; Lemay, Clark, \& Feeney, 2007).

There were few gender differences in the effects of positive relationship processes on perceived adaptation to parenthood. Only fathers', but not mothers', change in trust over time influenced adaptation for both fathers and mothers. The difference in trust may be due to gender differences in changes in interdependence across the transition to parenthood as interdependence fosters trust (Simpson, 2007). Applying evolutionary insights to the transition to parenthood, women feel perhaps more interdependence, and more stable, in their relationship than men when they have children due to their greater parental investment (Floyd \& Haynes, 2005). This is in line with the findings in this article that fathers' trust, on average, changed across the transition to parenthood, whereas mothers' trust remained stable. However, we cannot rule out that the null effects of mothers' change in trust are due to a lack of power caused by the relatively small sample size. The confidence intervals showed an upper limit much higher than zero for the effects of mothers' change in trust over time, indicating that power may have been too low to find these effects. Thus, a larger sample size would provide a more powerful test of the effects of mothers' trust. Because individual variation in change over time is used to estimate the effects, a lack of variance in mothers' trust (the variance in the slope of mothers' trust was significant but very small, .006) could also be a reason for the null findings. This does not seem a likely explanation for the null findings, however, as several slopes of perceived responsiveness and gratitude also had small variances but nonetheless still predicted adaptation.

\section{Strengths and limitations}

A strength of this study is that our data collection started before couples became pregnant, up to several years prior. Prepregnancy measurements are quite rare in the transition to parenthood literature. Our data therefore offer a stronger test of predictors of adaptation to parenthood than is usually possible as decreases across time could not be attributed to declines to baseline after a "pregnancy high" in this study. In addition, the APIM allowed us to explore the interdependence between partners and how they influence each other's 
adaptation to parenthood. Finally, we used a broad measure of how parents experienced their own adaptation to parenthood, covering several dimensions. We believe this provides a more accurate assessment of perceived adaptation as a decrease in only one dimension is not necessarily a sign of low adaptation to parenthood. A reported decline in relationship satisfaction may, for example, indicate that the couple's main focus has switched from the relationship toward the child, but the couple may still experience an easy adaptation to parenthood.

As previously stated, the data set also posed a number of limitations. Due to the difficulty of obtaining prepregnancy data, the sample size was modest. This limited the power of some of the effects, particularly the effects of mothers' change in trust over time; resulted in modest model fit; and limited the complexity of the models that we were able to test. A model including all three variables would allow the disentanglement of the underlying relations between responsiveness, gratitude, and trust and how they impact adaptation to parenthood. This would further allow for the conceptual integration of these three relationship variables. Future studies using larger data sets that allow for the integration of these relationship processes would be an interesting and valuable addition to the literature.

Another limitation is that because couples were followed from before pregnancy, childbirth took place at different time points, making the slopes in the models unbalanced on time. We corrected for this as much as possible by adding time since childbirth to the models as a covariate. We also ran the models correcting for birth cohort in the slopes, and this yielded the same results. When time is completely unbalanced, each time point may only contain one data point, leading to interpretation problems. However, because there were only three birth cohorts, each time point still contained many data points, similar to data that are balanced on time. We believe, therefore, that the influence of this timing problem on the results is limited. However, we cannot rule out that there were nonlinear changes over time that could not be detected through our method of analysis.
Our sample of married couples might not be representative of the Dutch population as many Dutch children are born to unmarried parents (45.3\% in 2011; Statistics Netherlands, 2012). Norwegian data showed that changes in relationship satisfaction across the transition to parenthood were similar for married and cohabiting mothers, but cohabiting mothers had lower initial satisfaction (Mortensen, Torsheim, Melkevik, \& Thuen, 2012). Initial levels of positive relationship processes prior to childbirth might thus be lower among cohabiting couples than among married couples. However, we would not expect the predictors of adaptation to parenthood to be substantially different for the two groups.

Self-report methods have limitations such as biased responses and socially desirable answering patterns. As such, adaptation to parenthood as measured in this study was a person's judgment and report of their own adaptation, which is not necessarily the same as actual changes in parental well-being measured by quantifiable behavior. A strength of the self-report method is that it reflects how parents perceive their own feelings and circumstances, which can be a stronger predictor of well-being than observed behavior or the factual situation (Lyubomirsky, 2001). However, an important next step in validating these results would be to relate self-reports of adaptation to other indicators of adaptation, such as depressive symptoms across the transition to parenthood, observational data on how couples deal with relationship and conflict issues, or even more objective data such as diagnosed postnatal depression. Such a comparison could be used to test whether different methods of assessing adaptation to parenthood predict different outcomes in, for example, parental well-being or child development.

\section{Conclusion}

This study showed that the level of perceived partner responsiveness, gratitude, and trust that men and women feel even years before pregnancy predicted their experience of how well they have adapted to parenthood. Even more important was how these positive relationship processes changed across the transition to 
parenthood. Parents with increased perceived responsiveness, gratitude, and trust over time or whose partner reported increases over time experienced a better adaptation to parenthood than parents who reported decreases across the transition. Positive relationship processes are not necessarily stable, and our results imply that interventions that help first-time parents to increase their positive relationship processes across the transition to parenthood could be beneficial. Future research should focus on how these positive relationship processes are interrelated to one another.

\section{References}

Akaike, H. (1973). Information theory and an extension of the maximum likelihood principle. In B. N. Petrov \& F. Csáki (Eds.), 2nd International Symposium on Information Theory, Tsahkadsor, Armenia, USSR, September 2-8, 1971 (pp. 267-281). Budapest, Hungary: Akadémiai Kiadó.

Alexander, R., Feeney, J., Hohaus, L., \& Noller, P. (2001). Attachment style and coping resources as predictors of coping strategies in the transition to parenthood. Personal Relationships, 8, 137-152. https://doi.org/10. 1111/j.1475-6811.2001.tb00032.x

Algoe, S. B., Gable, S. L., \& Maisel, N. C. (2010). It's the little things: Everyday gratitude as a booster shot for romantic relationships. Personal Relationships, 17, 217-233. https://doi.org/10.1111/j.1475-6811.2010. 01273. $\mathrm{x}$

Algoe, S. B., Haidt, J., \& Gable, S. L. (2008). Beyond reciprocity: Gratitude and relationships in everyday life. Emotion, 8, 425-429. https://doi.org/10.1037/15283542.8.3.425

Algoe, S. B., \& Stanton, A. L. (2012). Gratitude when it is needed most: Social functions of gratitude in women with metastatic breast cancer. Emotion, 12, 163-168. https://doi.org/10.1037/a0024024

Amato, P. R. (2001). Children of divorce in the 1990s: An update of the Amato and Keith (1991) meta-analysis. Journal of Family Psychology, 15, 355-370. https:// doi.org/10.1037/0893-3200.15.3.355

Aronson, E., \& Lindner, D. (1965). Gain and loss of esteem as determinants of interpersonal attractiveness. Journal of Experimental Social Psychology, 1, 156-171. https://doi.org/10.1016/0022-1031(65)90043-0

Bakan, D. (1966). The test of significance in psychological research. Psychological Bulletin, 66, 423-437. https:// doi.org/10.1037/h0020412

Bartlett, M. Y., \& DeSteno, D. (2006). Gratitude and prosocial behavior: Helping when it costs you. Psychological Science, 17, 319-325. https://doi.org/10.1111/j .1467-280.2006.01705.x

Belsky, J., \& Rovine, M. (1990). Patterns of marital change across the transition to parenthood: Pregnancy to three years post-partum. Journal of Marriage and the Family, 52, 5-20. https://doi.org/10.2307/352833
Bolger, N., Zuckerman, A., \& Kessler, R. C. (2000). Invisible support and adjustment to stress. Journal of Personality and Social Psychology, 79, 953-961. https:// doi.org/10.1037/0022-3514.79.6.953

Byrne, B. M., \& Crombie, G. (2003). Modeling and testing change: An introduction to the latent growth curve model. Understanding Statistics, 2, 177-203. https:// doi.org/10.1207/S15328031US0203_02

Campbell, L., \& Kashy, D. A. (2002). Estimating actor, partner, and interaction effects for dyadic data using PROC MIXED and HLM: A user friendly guide. Personal Relationships, 9, 327-342. https://doi.org/10. 1111/1475-6811.00023

Canevello, A., \& Crocker, J. (2010). Creating good relationships: Responsiveness, relationship quality, and interpersonal goals. Journal of Personality and Social Psychology, 99, 78-106. https://doi.org/10. 1037/a0018186

Colegrave, N., \& Ruxton, G. D. (2003). Confidence intervals are a more useful complement to nonsignificant tests than are power calculations. Behavioral Ecology, 14, 446-447. https://doi.org/10.1093/beheco/14.3.446

Debrot, A., Cook, W. L., Perrez, M., \& Horn, A. B. (2012). Deeds matter: Daily enacted responsiveness and intimacy in couples' daily lives. Journal of Family Psychology, 26, 617-627. https://doi.org/10.1037/ a0028666

Doss, B. D., Rhoades, G. K., Stanley, S. M., \& Markman, H. J. (2009). The effect of the transition to parenthood on relationship quality: An 8-year prospective study. Journal of Personality and Social Psychology, 96, 601-619. https://doi.org/10.1037/a0013969

Emmons, R. A., \& McCullough, M. E. (2004). The psychology of gratitude. New York, NY: Oxford University Press.

Finkenauer, C., Kerkhof, P., Righetti, F., \& Branje, S. (2009). Living together apart: Perceived concealment as a signal of exclusion in marital relationships. Personality and Social Psychology Bulletin, 35, 1410-1422. https://doi.org/10.1177/ 0146167209339629

Floyd, K., \& Haynes, M. T. (2005). Applications of the theory of natural selection to the study of family communication. Journal of Family Communication, 5(2), 79-101. https://doi.org/10.1207/s15327698jfc0502_2

Fredrickson, B. L. (2001). The role of positive emotions in positive psychology: The broaden-andbuild theory of positive emotions. American Psychologist, 56, 218-226. https://doi.org/10.1037/0003-066X. 56.3.218

Fredrickson, B. L., \& Joiner, T. (2002). Positive emotions trigger upward spirals toward emotional well-being. Psychological Science, 13, 172-175. https://doi.org/ 10.1111/1467-9280.00431

Fredrickson, B. L., Mancuso, R. A., Branigan, C., \& Tugade, M. M. (2000). The undoing effect of positive emotions. Motivation and Emotion, 24, 237-258. https://doi.org/10.1023/A:1010796329158

Goodman, J. H. (2004). Paternal postpartum depression, its relationship to maternal postpartum depression, and implications for family health. Journal of Advanced 
Nursing, 45, 26-35. https://doi.org/10.1046/j.13652648.2003.02857

Hoenig, J. M., \& Heisey, D. M. (2012). The abuse of power. The American Statistician, 55, 19-24. https:// doi.org/10.1198/000313001300339897

Howard, K. S., \& Brooks-Gunn, J. (2009). Relationship supportiveness during the transition to parenting among married and unmarried parents. Parenting: Science and Practice, 9(1-2), 123-142. https://doi.org/ 10.1080/15295190802656828

Huston, T. L., Caughlin, J. P., Houts, R. M., Smith, S. E., \& George, L. J. (2001). The connubial crucible: Newlywed years as predictors of marital delight, distress, and divorce. Journal of Personality and Social Psychology, 80, 237-252. https://doi.org/10.1037/0022-3514.80. 2.237

Karney, B. R., \& Bradbury, T. N. (1995). The longitudinal course of marital quality and stability: A review of theory, method, and research. Psychological Bulletin, 118,3-34. https://doi.org/10.1037/0033-2909.118.1.3

Kashy, D. A., \& Kenny, D. A. (2000). The analysis of data from dyads and groups. In H. T. Reis \& C. M. Judd (Eds.), Handbook of research methods in social psychology (pp. 451-477). New York, NY: Cambridge University Press.

Kluwer, E. S. (2010). From partnership to parenthood: A review of marital change across the transition to parenthood. Journal of Family Theory and Review, 2, 105-125. https://doi.org/10.1111/j.1756-2589.2010. 00045.x

Kluwer, E. S., \& Johnson, M. D. (2007). Conflict frequency and relationship quality across the transition to parenthood. Journal of Marriage and the Family, 69, 1089-1106. https://doi.org/10.1111/j.1741-3737. 2007.00434.x

Koranyi, N., \& Rothermund, K. (2012). Automatic coping mechanisms in committed relationships: Increased interpersonal trust as a response to stress. Journal of Experimental Social Psychology, 48, 180-185. https:// doi.org/10.1016/j.jesp.2011.06.009

Kubacka, K. E., Finkenauer, C., Rusbult, C. E., \& Keijsers, L. (2011). Maintaining close relationships: Gratitude as a motivator and a detector of maintenance behavior. Personality and Social Psychology Bulletin, 37, 1362-1375. https://doi.org/10.1177/ 0146167211412196

Kurdek, L. A. (1991). Marital stability and changes in marital quality in newly wed couples: A test of the contextual model. Journal of Social and Personal Relationships, 8, 27-48. https://doi.org/10.1177/ 0265407591081002

Langrock, A. M., Compas, B. E., Keller, G., Merchant, M. J., \& Copeland, M. E. (2002). Coping with the stress of parental depression: Parents' reports of children's coping, emotional, and behavioral problems. Journal of Clinical Child and Adolescent Psychology, 31, 312-324. https://doi.org/10.1207/ S15374424JCCP3103_03

Larzelere, R. E., \& Huston, T. L. (1980). The Dyadic Trust Scale: Toward understanding interpersonal trust in close relationships. Journal of Marriage and the Family, 42, 595-604. https://doi.org/10.2307/351903

Lawrence, E., Rothman, A. D., Cobb, R. J., Rothman, M. T., \& Bradbury, T. N. (2008). Marital satisfaction across the transition to parenthood. Journal of Family Psychology, 22, 41-50. https://doi.org/10.1037/08933200.22.1.41

Lemay, E. P., Jr., \& Clark, M. S. (2008). How the head liberates the heart: projection of communal responsiveness guides relationship promotion. Journal of Personality and Social Psychology, 94, 647-671. https://doi. org/10.1037/0022-3514.94.4.647

Lemay, E. P., Jr., Clark, M. S., \& Feeney, B. C. (2007). Projection of responsiveness to needs and the construction of satisfying communal relationships. Journal of Personality and Social Psychology, 92, 834-853. https:// doi.org/10.1037/0022-3514.92.5.834

Lewis, T., \& Manusov, V. (2009). Listening to another's distress in everyday relationships. Communication Quarterly, 57, 282-301. https://doi.org/10.1080/0146 3370903107279

Lyubomirsky, S. (2001). Why are some people happier than others? The role of cognitive and motivational processes in well-being. American Psychologist, 56, 239-249. https://doi.org/10.1037/0003066X.56.3.239

Maisel, N. C., \& Gable, S. L. (2009). The paradox of received social support: The importance of responsiveness. Psychological Science, 20, 928-932. https://doi. org/10.1111/j.1467-9280.2009.02388.x

McCullough, M. E., Emmons, R. A., \& Tsang, J. (2002). The grateful disposition: A conceptual and empirical topography. Journal of Personality and Social Psychology, 82, 112-127. https://doi.org/10.1037/0022-3514. 82.1 .112

Mortensen, Ø., Torsheim, T., Melkevik, O., \& Thuen, F. (2012). Adding a baby to the equation. Married and cohabiting women's relationship satisfaction in the transition to parenthood. Family Process, 51, 122-139. https://doi.org/10.1111/j.1545-5300.2012.01384.x

Muthén, L. K., \& Muthén, B. O. (1998-2015). Mplus user's guide (7th ed.). Los Angeles, CA: Muthén \& Muthén.

O'Hara, M. W., \& Swain, A. M. (1996). Rates and risk of postpartum depression: A meta-analysis. International Review of Psychiatry, 8, 37-54. https://doi.org/ 10.3109/09540269609037816

Pedhazur, E. J. (1982). Multiple regression in behavioral research: Explanation and prediction (2nd ed.). New York, NY: Holt, Rinehart, \& Winston.

Peugh, J. L., DiLillo, D., \& Panuzio, J. (2013). Analyzing mixed-dyadic data using structural equation models. Structural Equation Modeling: A Multidisciplinary Journal, 20,314-337. https://doi.org/10.1080/ 10705511.2013.769395

Reis, H. T., Clark, M. S., \& Holmes, J. G. (2004). Perceived partner responsiveness as an organizing construct in the study of closeness and intimacy. In D. J. Mashek \& A. Aron (Eds.), Handbook of closeness and intimacy (pp. 201-225). Mahwah, NJ: Erlbaum. 
Rempel, J. K., Holmes, J. G., \& Zanna, M. P. (1985). Trust in close relationships. Journal of Personality and Social Psychology, 49, 95-112. https://doi.org/10. 1037/0022-3514.49.1.95

Shapiro, A. F., Gottman, J. M., \& Carrère, S. (2000). The baby and the marriage: Identifying factors that buffer against decline in marital satisfaction after the first baby arrives. Journal of Family Psychology, 14, 59-70. https://doi.org/10.1037/0893-3200.14.1.59

Simpson, J. A. (2007). Psychological foundations of trust. Current Directions in Psychological Science, 16, 264-268. https://doi.org/10.1111/j.1467-8721.2007. 00517.x

Simpson, J. A., Rholes, W. S., Campbell, L., Tran, S., \& Wilson, C. L. (2003). Adult attachment, the transition to parenthood, and depressive symptoms. Journal of Personality and Social Psychology, 84, 1172-1187. https://doi.org/10.1037/0022-3514.84.6.1172

Spanier, G. B. (1976). Measuring dyadic adjustment: New scales for assessing the quality of marriage and similar dyads. Journal of Marriage and the Family, 38, 15-28. https://doi.org/10.2307/350547

Stapleton, L. R. T., Schetter, C. D., Westling, E., Rini, C., Glynn, L. M., Hobel, C. J., \& Sandman, C. A. (2012). Perceived partner support in pregnancy predicts lower maternal and infant distress. Journal of Family Psychology, 26, 453-463. https://doi.org/10. 1037/a0028332

Statistics Netherlands. (2012). Births to unmarried parents and paternity acknowledgements. Retrieved from
http://www.cbs.nl/nl-NL/menu/themas/veiligheidrecht/publicaties/artikelen/archief/2012/2012-3719wm.htm

Steffensmeier, R. H. (1982). A role model of the transition to parenthood. Journal of Marriage and Family, 44, 319-334. https://doi.org/10.2307/351542

Tice, D. M., Baumeister, R. F., Shmueli, D., \& Muraven, M. (2007). Restoring the self: Positive affect helps improve self-regulation following ego depletion. Journal of Experimental Social Psychology, 43, 379-384. https://doi.org/10.1016/j.jesp.2006.05.007

Twenge, J. M., Campbell, W. K., \& Foster, C. A. (2003). Parenthood and marital satisfaction: A meta-analytic review. Journal of Marriage and the Family, 65, 574-583. https://doi.org/10.1111/j.1741-3737.2003. 00574.x

Wieselquist, J., Rusbult, C. E., Foster, C. A., \& Agnew, C. R. (1999). Commitment, pro-relationship behavior, and trust in close relationships. Journal of Personality and Social Psychology, 77, 942-966. https://doi.org/ 10.1037/0022-3514.77.5.942

Wood, A. M., Maltby, J., Gillett, R., Linley, P. A., \& Joseph, S. (2008). The role of gratitude in the development of social support, stress, and depression: Two longitudinal studies. Journal of Research in Personality, 42, 854-871. https://doi.org/10.1016/j.jrp.2007. 11.003 